\title{
Orchard-system configurations increase efficiency, improve profits in peaches and nectarines
}

\author{
Kevin R. Day \\ Theodore M. DeJong \\ R. Scott Johnson
}

Simply put, a fruit tree can be viewed as a solar collector that converts sunlight into fruit. The more efficiently this is done, the greater the potential yield and profit. Consequently, growers face an important question when planting an orchard - what planting system to use? While varieties can be changed rather easily through grafting, the spacing, rootstock and conformation aspects of an orchard are typically permanent until that orchard is removed entirely, usually only after 15 to 20 years. These aspects can have profound effects on orchard productivity. Research conducted at the UC Kearney Research and Extension Center on orchard systems - including higher-density plantings and pruning techniques that enhance light interception - has allowed growers to make better-informed decisions when planting new orchards.

The productivity of an orchard de1 pends in part on how well it collects sunlight. As such, "light interception" is a function of the density, height and shape of the trees, which in turn incorporates the number, angle and orientation of their branches. These characteristics are the primary components of what is called a "planting system." The ideal orchard planting system can vary based on numerous factors, including geographic location, variety and species, soil type, rootstock, and local cultural and economic concerns. However, each system has inherent qualities that, if understood, can be used to help growers meet their goals for the orchard. UC pomologists have been studying and elucidating these planting-system characteristics at the

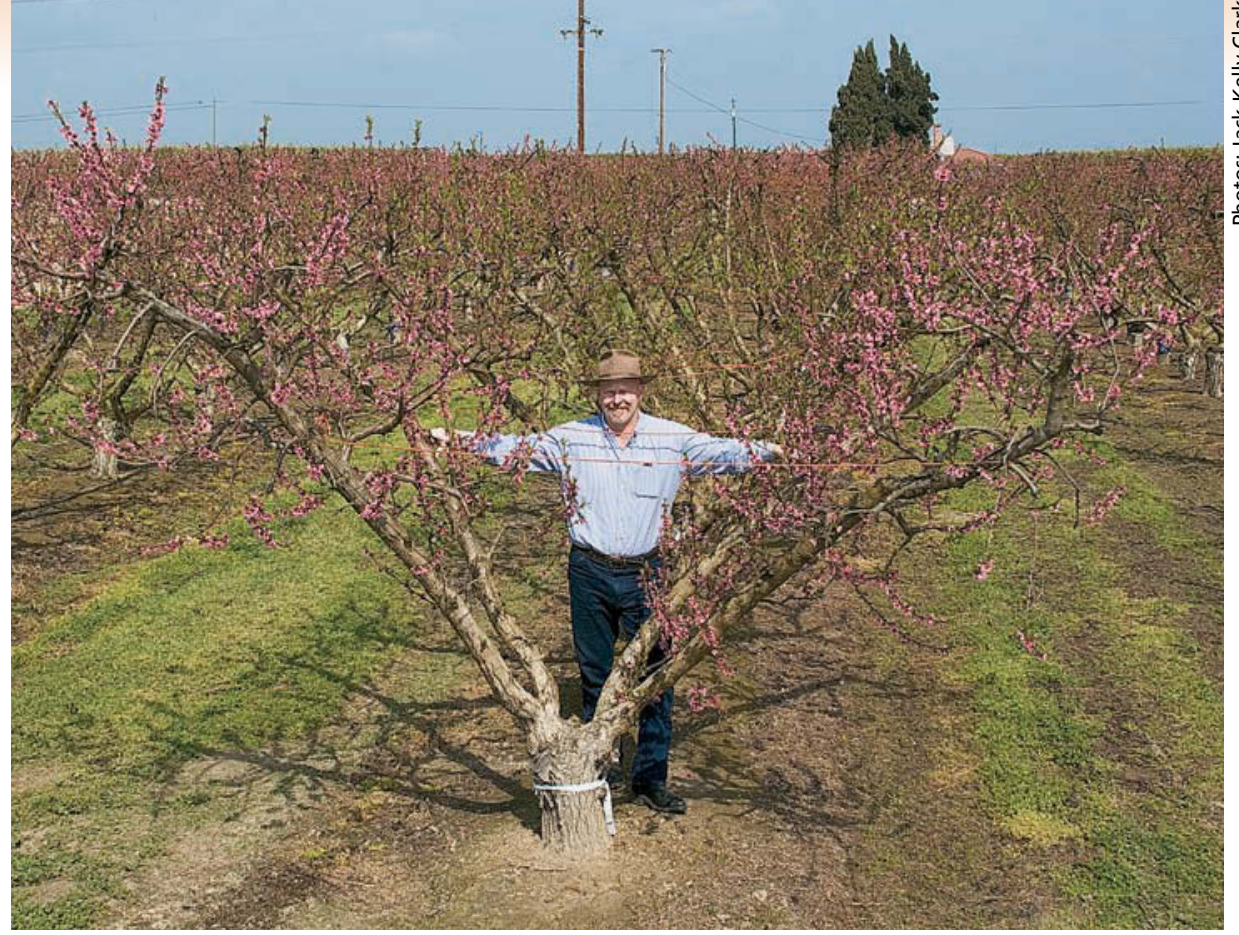

Tree form and height are two key factors in determining how efficiently stone fruit orchards produce fruit and grower profitability. Kevin Day, UC Cooperative Extension tree fruit farm advisor in Tulare County, above, is one of the principal UC scientists involved in studying different tree systems. The Quad-V orchard shown is a popular high-density system. Right, the traditional "open vase" peach tree is less uniform and thus more costly to maintain.

UC Kearney Research and Extension Center (KREC) for more than 30 years, in order to help growers develop profitable and sustainable orchards.

\section{Production in orchard systems}

Since the inception of the freshshipping tree fruit industry shortly after the California Gold Rush (during the 1860s and 1870s) the state's dominant orchard system has been the open vase, with trees trained into a wide "cone" tree shape at relatively ample spacings within the orchard. Originally, trees were planted on wide, 22-to-25-foot spacings (70 to 90 trees per acre) in both directions to allow for easy access by horses, mules and the primitive mechanized equipment that was then available. However, such wide-spaced systems came into

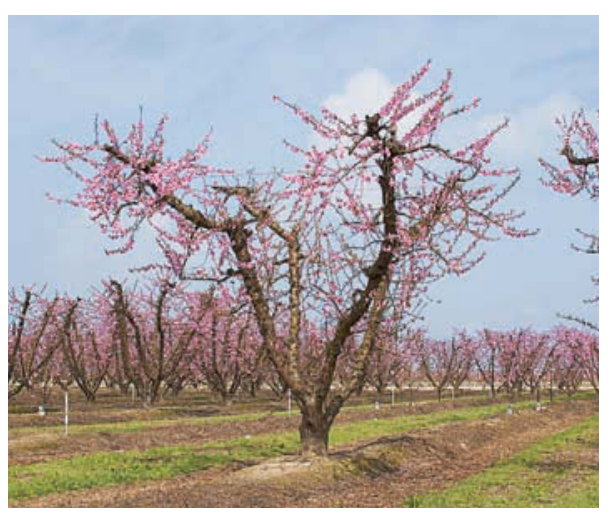

production slowly because the trees must grow for many years before they reach full size. One of the basic axioms of planting-system design is that a tree should fill its allotted space as quickly as possible, and having done so, be maintained easily within that space.

Growers were able to reduce spacings somewhat in the 1950s due to the introduction of chemical herbicides, which reduced and sometimes even eliminated the need for crosscultivation. Cross-cultivation is cultivating across the rows of the orchards instead of just down the row; it was 


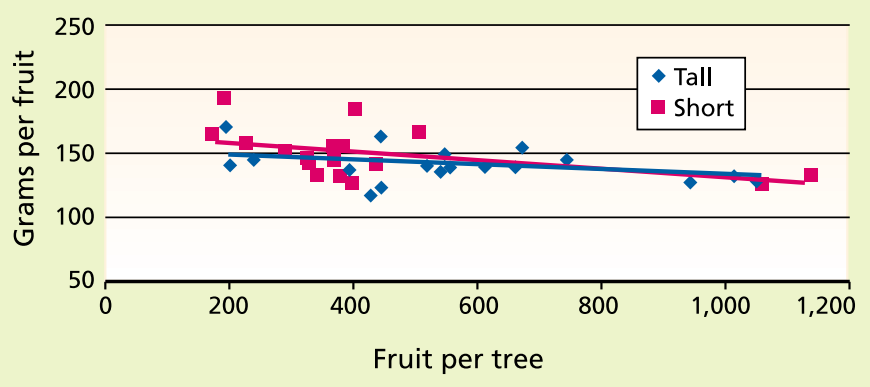

Fig. 1. Relationship between fruit size and crop load for short (limited height) and tall (standard height) 'Summer Bright' nectarine trees pruned to a Quad-V conformation.

nomics rather than on simply trying to maximize production.

Cling peaches trial. To explore the economics of orchard systems, in 1990 a replicated block of 'Ross' processing (cling) peaches was planted at Kearney (DeJong et al. 1999). This trial orchard compared four planting systems with different spacings: KAC-V (6.5 feet by 18 feet), high-density (HiD) KAC-V (5.5 feet by 15 feet), cordon ( 8 feet by 13 feet, and height limited to 7 feet) and open vase (16 feet by 18 feet). The HiD $\mathrm{KAC}-\mathrm{V}$ system is even more closely planted than the KAC-V, with the goal of even more rapid full production. The cordon system consists of a single tall trunk, about 3 feet high; scaffolds are bent down off of the trunk in the first and second growing season and tied to a temporary support rope that is suspended down the row at a height of 4 to 5 feet. By tying the scaffolds down, earlier fruiting is induced and tree height is reduced, with the goal of maintaining a tree height in which all labor operations can be performed from the ground without a ladder. The orchard was 8 acres total, with four replications of each system in 0.5 -acre experimental units. All associated costs and yields were recorded annually for the first 5 years after planting.

In this experiment, the two KAC-V systems were the most productive and profitable despite having the highest establishment, development and production costs (table 4). It is important to note, however, that this trial also vividly demonstrated that the development and initial production costs of these high-density systems were $50 \%$ to $100 \%$ greater than those of the traditional open-vase system. Due to the detailed record-keeping, this trial also provided tools that growers could use to estimate relative orchard profitability given particular price, cost and yield scenarios.

One surprising result of this study was that although the limited-height cordon system eliminated the use of ladders, this system still did not have lower per-acre labor costs. One of the primary beliefs in fruit production is that ladders add appreciably to the cost of labor since they are heavy and awkward to maneuver, and any time spent ascending or descending them is time lost for the primary tasks of pruning, thinning and harvesting. Since labor accounts for the majority of the orchard costs associated with fruit production - often $\$ 2,000$ to $\$ 3,000$ per acre annually - eliminating ladders should represent a potentially significant labor savings.

However, a physiological analysis of the cordon systems in this experiment indicated that potential economic efficiencies from lowering tree heights were not realized because training cordons to a horizontal position stimulated excessive vegetative growth (Grossman and DeJong 1998). This both increased pruning costs and decreased the trees' allocation of dry matter into fruit, reducing fruit yields. It became clear that if tree heights were to be reduced, it must be done in a manner that does not stimulate vegetative growth (vigor) at the expense of fruit growth.

Nectarine trial. To better understand the relationship between tree height and labor costs, a study with the KAC-V and Quad-V systems was begun at Kearney in 1995 (Day et al. 2003), with a replicated block of 'Summer Bright' nectarine trees growing as either twoleader (scaffold) KAC-Vs or four-leader Quad-Vs (6-feet-by-18-feet and 9-feetby-18-feet spacing, respectively). Tree height was either allowed to develop to the common standard of 12 to 13 feet or limited to 8 to 9 feet, which meant that much of the hand labor could be performed without ladders. In order to get comparable planar bearing area between the two system heights, the limbs of the shorter trees were flattened by tying them to an angle of 50 degrees from horizontal, thereby achieving a shorter, flatter tree than is typical for California.

The results demonstrated that the labor costs for the short trees were an average of $20 \%$ to $30 \%$ less, depending on the activity, than those of tall trees. In addition, the yield potential was similar for short and tall trees (fig. 1), which was somewhat surprising and defied conventional wisdom. However, due to the flattened limb orientation, both systems had similar planar volumes and virtually identical light-interception characteristics, making it not unreasonable to assume that yields should be similar as well. Additional research will be necessary to explore the role of these factors in other locations and with different tree varieties.

As noted, one of the concerns associated with short trees is that of excess vigor. In this study, care was taken to ensure that the trees were not overwatered or overfertilized, and there was no problem with excessive vigor. However, this may not always be possible under all growing conditions and with all cultivars. The ultimate solution to the problem of excess vigor lies in developing adequate dwarfing root- 


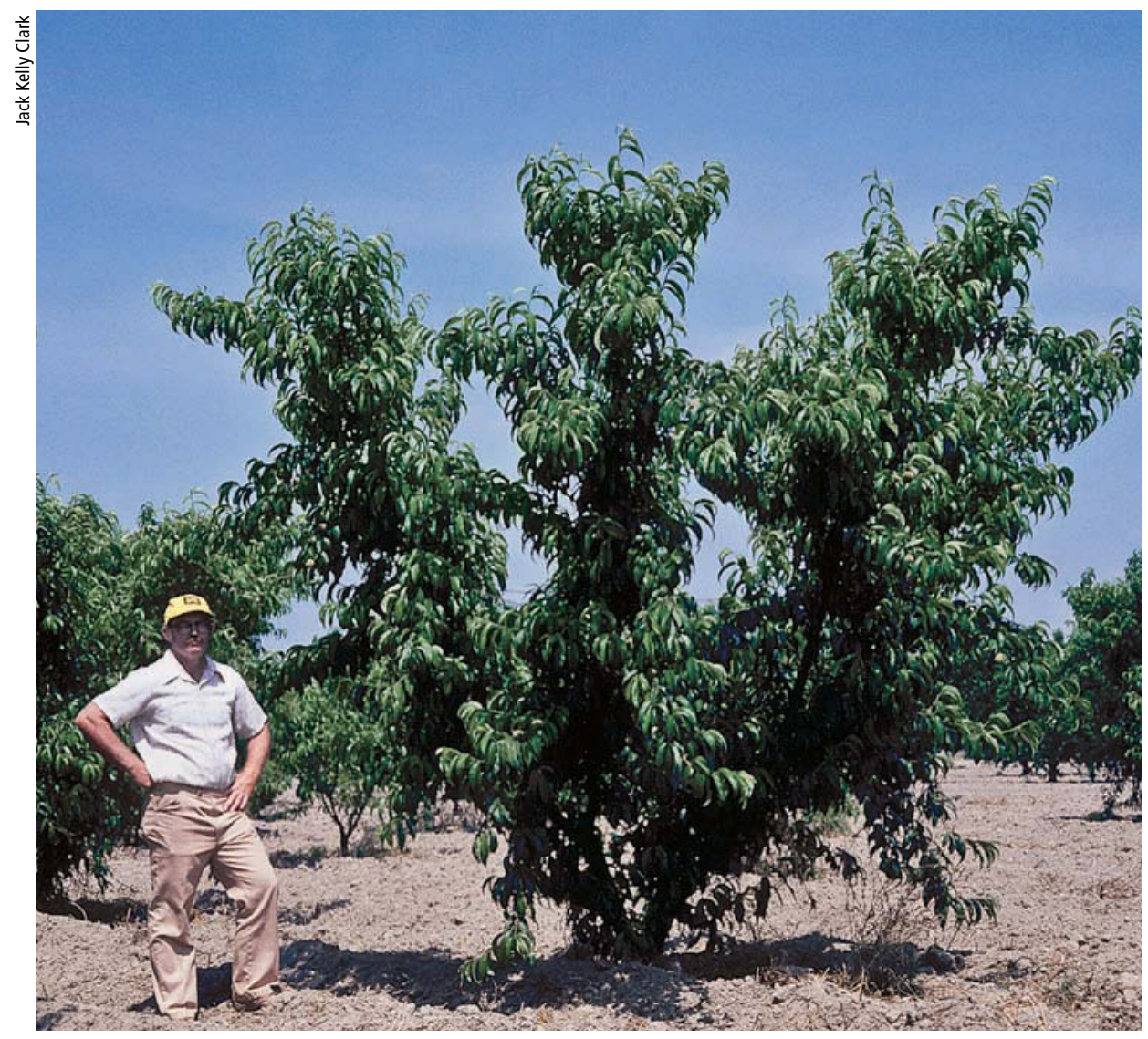

California's tree fruit industry developed shortly after the Gold Rush of the mid-nineteenth century. For many years the state's dominant orchard system was the open vase, with trees trained into a wide " $\mathrm{V}$ " shape and ample spacing, allowing for $\mathbf{7 0}$ to 90 trees per acre. Above, long-time UC technician Jim Doyle stood next to a standard peach tree in the late 1970s.

stocks to fit a range of orchard needs such as variety, season of ripening, soil type and $\mathrm{pH}$.

\section{Maintaining competitive orchards}

To remain competitive in an increasingly global market, the California fruit industry must develop orchard systems that (1) are simple and easily understood by managers and workers, (2) are of appropriate cost relative to the potential return on investment, (3) minimize reliance on ladders, which increase labor costs and (4) ensure the production of high-quality and high-value fruit.

Regimented systems such as the KAC-V and the Quad-V are quickly becoming the norm for many growers. These systems can be successfully planted without having to alter rowspacings or purchase new equipment. There is also a trend toward somewhat reduced tree heights as growers come to understand the importance of light and its relationship to tree height and form. Just because a tree is tall does not ensure that it is inherently more productive or intercepts light more efficiently than a shorter tree. Furthermore, fresh-shipping tree fruits are somewhat unique in that there is frequently an economic reward for increased quality rather than just an emphasis on total production. The Kearney research efforts have helped shape grower understanding of the relationship between potential yield and the most profitable yield.

The stone-fruit industry needs the development of a proven dwarfing rootstock that can be relied upon to ameliorate the problem of excessive vigor in short trees. Currently, growers still question whether tree heights can be dramatically reduced in a simple, effective and sustainable manner. Research at Kearney is now focusing on developing such dwarfing rootstocks, which could potentially revolutionize production in the stone-fruit industry just as they did in the apple industry (Ferree and Carlson 1987). Next, additional research will be needed to develop sensible and successful training systems that match the growth and production characteristics of trees on these dwarfing rootstocks.

K.R. Day is Tree Fruit Farm Advisor, UC Cooperative Extension, Tulare County; and T.M. DeJong is Professor and Cooperative Extension Specialist, and R.S. Johnson is Pomology Specialist, Department of Plant Sciences, UC Davis.

\section{References}

Day KR, Johnson RS, Crisosto $C$, et al. 2003. Tree height and volume studies for fresh-shipping stone fruits. California Tree Fruit Agreement Research Reports for 2002. The California Tree Fruit Agreement, Reedley Calif. 5 p. www.eatcaliforniafruit.com/ growers-shippers/research.

Day KR, Johnson RS, DeJong TM. 1993. Evaluation of new techniques for improving stone fruit production, fruit quality, and storage performance: High density training trials. California Tree Fruit Agreement Annual Research Report. 7 p. www.eatcaliforniafruit. com/growers-shippers/research.

DeJong T, Day K, Doyle J, Johnson S. 1991. Evaluation of training/pruning systems of peach, plum and nectarine trees in California. Acta Hort 322:99-106.

DeJong TM, Tsuji W, Doyle JF, Grossman YL. 1999. Comparative economic efficiency of four peach production systems in California. HortScience 34(1):738.

Ferree DC, Carlson RF. 1987. Apple rootstocks. In: Rom RC, Carlson RF (eds.). Rootstocks for Fruit Crops. New York: J Wiley. p 107-43.

Gerdts M, Andris H, Beutel J. 1979. High density goes big time. Fruit Grower:9-10.

Grossman YL, DeJong TM. 1998. Training and pruning system effects on vegetative growth potential, light interception and cropping efficiency in peach trees. J Amer Soc Hort Sci 123:1058-64. 